\title{
The Application of Shape Rule in Web Page Design
}

\author{
Yi Shan ${ }^{1, a}$ \\ ${ }^{1}$ Zhengzhou University of Industrial Technology, Zhengzhou, Henan, 451100 \\ ${ }^{\mathrm{a}}$ email
}

\section{Keywords: Shape Rules, Web Design, Application Design}

\begin{abstract}
With the continuous development of society, the network has become an important mode of contact with people's lives. Web design from the simplest design pattern is now transformed into colorful web effect. Web design is the most important application of the law is the law of the shape, the shape of the law can be said to constitute the main elements of web design. Web design is changing the shape of the effect, the effect of different shapes used to generate web pages are different, the need to refer to the time of the network environment, web designers should pay attention to the diversification of the page effect, to avoid one design shape in the form of abuse, causing people's visual fatigue. Web design can be said that no rules to follow to follow is to serve the public, to meet the current trend of social development. Web design process to follow certain rules of shape design occupies an important position, is the key to constitute the entire web interface, as well as page views of the weathervane. From web design features, the shape of the law in web design application to analyze.
\end{abstract}

\section{Introduction}

As network technology continues to improve, high-paced lifestyle network platform has become the platform of choice for service the moment, many units and individuals are aware of the network can use the virtual platform for the dissemination and collection of resources, have the structures corresponding network platform, in order to generate web design, web design and now as a professional website design, has gradually become known as an application of the technology. The shape of the law as an important factor in web design, web design and integration of the entire process, including the home page design, the layout, graphics, and other modifications. Its purpose is to be able to make that web page information accurately, systems, effective communication. Expand the influence of the site, increase site views, in order to increase website revenue.

Application of law in the shape of web design, on the promotion of the site, occupies an important position, the fusion site's home page design, shape elements can not be separated, and how to use the shape of the law is something we get to the bottom of the problem.

\section{Web design feature}

Many factors to consider web design, into a lot of social and human factors, it is important is the combination of technology. Progress of science and technology in order to bring the whole network environment to move forward towards a harmonious, high-speed. There are three basic configuration page: graphics, text, color. Wherein the use of a pattern shape is the most important factor, the first page can give viewers impressed content publishing off surface, improve the attractiveness of content, allowing web surfers to web impressed; secondly graphic shape elements combined color elements, concept tone in line with the public's aesthetic, graphical shape to have fun, so to some extent be able to attract web surfers interested in the page with a browser to go curiosity; again is to pay attention to the size and shape of the tone whether coordination, popular in terms of page views and the main color coordination has a direct relationship between the shape of the page you want to meet the needs of the page.

Page is a product of a new era, unlike traditional media, is induction of unilateral way, Web users and the users are able to interact with each other, and the identity and the identity of the audience of 
users not specifically targeted, they are information recipient also disseminators of information. This requirement is designed to meet web users to communicate with friends between, allowing users to interact between, which means the design level of the entire page is a test. Network environment like a big melting pot, inclusive many kinds of people. Receive information and dissemination of information is mutual, each page viewers have the right to participate in the web page information receiving, processing, release, is completely free, everyone has the opportunity to participate, everyone is our culture receiving body. Compared to traditional media, the public can only accept single channel feedback, Web is a platform, such as dating sites century good margin, with the targeted, for unmarried men and women. Web site design Jiayuan show is a platform for mutual exchange, added to the web platform approach is diversified, relatively detailed information presented is based.

A good website will be continuously promote the public, web design need to integrate the public's attention, the need to constantly maintain the background, to keep pace with the times. After the designer can be transmitted to the host page, on which the layout, color, etc. to be adjusted accordingly to achieve the best visual effects and convey effects. Now open network environment, development of web site need to pay attention to sustainable development principles, the need to constantly update in order to adapt to the current network environment.

Web design process to fully get a shape corresponding to the law, need to integrate a number of factors, which requires web designers to fully combine contemporary social environment for the page showing the characteristics of the times, such as many of the big sites, from the beginning easy mode, backstage after maintenance, revision highlights the characteristics of the page, innovation in line with the trend of network products, has been recognized by Internet users.

Now is the era of rapid development of information technology, web pages need to constantly update. The biggest advantage of web resources that her general pattern of utilization. Current page can combine graphics, text, sound, animation and other techniques. Formal performance can be said to be the sound of the line, and Mao.

Many of the advantages of using Web page now, is a combination of images and sounds, to attract the viewer's attention, increase page views, up to a certain publicity effect. With advances in network technology, network technology continues to improve, the expansion of broadband, the speed increase, prompting designers to more integrated use of various media elements to design web pages to meet and enrich viewers to the network transmission quality of information submitted higher requirements.

The current environment of open networks is that with the maturity of network technology, increase the promotion of the network, the number of Internet users is not short of showing an upward trend, especially now that the prevalence of intelligent machines, so more and more web design With modern. In web design, technology and art of combining a cultural trend, complementarity between them. Network technology and art combined with each other, closely integrated network technology and creative arts, to make art web design by graphic design extended to the three-dimensional design, expanded from a purely auditory art visual arts into the space, thus more attractive to viewers. This page requires designers to grasp the initiative of the current network technology exists now be artistic features combined.

\section{The Shape of the Law in Web Design Principles}

Web design requires a combination of many elements, the main three elements of graphics, text, titles. These three elements can form a variety of lines and shapes on the page, constitute the overall artistic effect composed of lines and shapes page. Shape case law is now indispensable design element of participation, how to use the law in the shape of web design, we need to take note of the points.

The shape of the law applied in web design, we need a reasonable use, not excessive use, excessive use can cause confusion web publishing. For objects of different pages, using the shape of the law is different: in the first formal official website, the use of the web-shaped line to pay attention to artistic effect, requirements, smooth, straight, rules, tidy, also known as wheeled there 
are profiles, showing page seriousness, solemnity. Repeat combination of straight lines and rectangles on a page can be presented in good order, entirely different visual effects. Followed by the youth literary home, the emphasis is on the use of the curve, the purpose is to constitute a relatively loose and free network environment, the generally applicable and dating sites on such good margin century, QQ space, micro-channel platform dating site. Since the flow of artistic effect curve is active, it has a dynamic. Repeat composite curves and arcs on a page can be rendered smooth, light, vibrant visuals, this is usually in the learning platform, for example on pages Ya classroom learning, wisdom tree learn web fine. Finally, comprehensive utilization curves and straight lines, this is a more open network environment, the purpose is to present a variety of web effects. Can certainly cause the viewer's interest, increase traffic to your pages, expanding the visibility of a web page, this is usually use on the website of the novel, the emphasis is on the content of continuity, richness.

Web design community is facing, so when the rule of web design shapes the most important element is the human element of integration. Audience of Internet users is web design, web design meets the public's perspective, we are able to get public support, to a certain extent, to see whether the page is able to cater to the needs of the public. Such as Taobao page revision in recent years, are more and more tends to be popular, thoughtful web design, shopping, payment for the integration of web design concept to meet the needs of the public.

Application of law in the shape of the main web design pay attention to cultural commonality above, the current network environment is more of an open environment, people's awareness of their rights is growing. Human beings are agents of social trends, the shape of the law of the page design to cater to the needs of the public, to keep up with the trend of the times, or the page will eventually be abandoned by the people. For example, the memory part 90 after Moore Park game page, updated to keep up with the times, the last being substituted League these big games. Web design is an ongoing process that requires a web designer in a timely manner according to the current needs of society, constantly on the content of the page will be revised, retain live page of visitors.

Web design is for different audiences, the requirements are not the same. When Fusion web design, pay attention to the use of Yuan Shu, show cultural change above an important factor to achieve the above cultural interaction.

Sometimes in order to make the entire page of systematic interface, you need to be patterned in the shape corresponding to the process in order to achieve a harmonious cultural factor above. Fig. 1 shows, for example, did not add a border and a border of the image, showing the effect is not the same, not the modified image on the page, causing confusion in the visual, and after the image is modified, can show a orderly way.
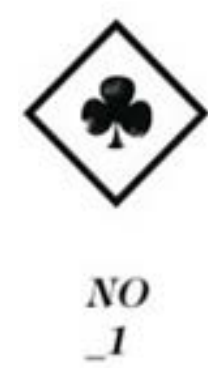
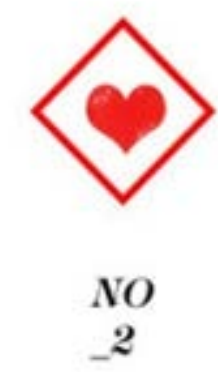

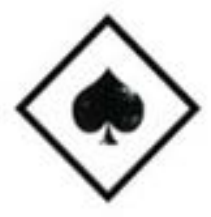

NO

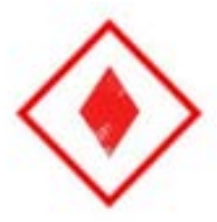

NO

Fig.1 The Visual

All kinds of web design, but with the characteristics of the page can have a fresh impression, web design follows the shape of the law, pay attention to innovation, in order to increase web traffic. Innovation is now selling web development, web development constraints shape the law is the law, we need a web designer on this basis, to innovate.

\section{Conclusion}

With economic development, network technology matures, the construction site is an art of living, 
reflected in all aspects of life, it requires a combination of various disciplines of knowledge, in order to perfect the art of presentation of a Web page, known by the public, accept promotion. The multimedia aspect of the construction site is currently the focus of development, construction sites, the most basic elements, that is, web design technology is mature, web design is an emerging network technology and art of combining design disciplines, both have the network basic features, as well as a comprehensive design concept.

\section{References}

[1] Zhang Fan, Luo Qi. Gong Xiaodong. Art Tutorials web interface design [M]. People Post Press, 2002.

[2] Li Dejun. Explore art and principles of web design [J]. Computer Knowledge and Technology, 2005 (12): 60.

[3] Wang Qingbin. modern web color design [J]. Wuxi light University: Social Sciences, 2001, (2)

[4] Zhang Fan, Luo Qi Gong Xiaodong web interface design Art Tutorials Beijing : People's Posts and Telecommunications Press, 2002: 2.

[5] Wen Xihua. Web design art and technique of Shaoyang University (Social Sciences), 2005, 4 (6): 115-116.

[6] Li Dejun. Explore art and principles of web design [J]. Computer Knowledge and Technology, 2005 (12): 60.

[7] Edward Yourdon, Carl Argila. computer networks and the Internet [M]. Beijing: Electronic Industry Press, 1998.

[8] Li Yanzu, Lu Ying. visual communication History and Aesthetics [M]. Beijing: China Renmin University Press, 2000

[9] Ma Li. Web design aesthetic horsepower analysis [J]. Yangtze Forum, 2008 (6): 89.

[10] Zeng Xiankai. Visual Communication Design [M]. Beijing: Beijing Institute of Technology Press, 2005. 